\title{
PARÂMETROS DE PROCESSO DE PINTURA QUE INFLUENCIAM A RESISTÊNCIA À CORROSÃO DOS AÇOS
}

Evandro de Azevedo Alvarenga '

\section{Resumo}

Os efeitos da limpeza superficial dos aços, da massa e da porosidade de camadas de fosfato e do tipo de resina eletroforética na resistência à corrosão atmosférica dos aços são estudados neste trabalho. Os testes de avaliação foram realizados em laboratório com corpos-de-prova pintados na indústria automobilística. Verifica-se que a limpeza superficial, medida pelos teores de resíduos carbonosos ou oleosos, deve ser menor que $8 \mathrm{mg} / \mathrm{m}^{2}$, de modo a não interferir na formação da camada de fosfato, cuja massa e porosidade devem ser menores que $3,5 \mathrm{~g} / \mathrm{m}^{2}$ e $1,5 \%$, respectivamente, para garantir ao sistema de pintura boa resistência à corrosão atmosférica. $O$ tipo de resina catiônica também influencia na resistência à corrosão dos aços. Os melhores resultados de resistência à corrosão foram obtidos com resina epóxi modificada.

Palavras-chave: Limpeza superficial; Fosfatização; Pintura; Resistência à corrosão atmosférica.

\section{PAINTING PROCESS PARAMETERS THAT INFLUENCE THE CORROSION RESISTANCE OF STEELS}

\begin{abstract}
The effects of surface cleanness, phosphate layers mass and porosity and the type of electrophoretic resin on the atmospheric corrosion resistance of steels are studied on this paper. The tests were carried out in laboratory with test specimens painted at the automobile industry. The results show that the surface cleanness, measured by carbon or oil residues contents, must be less than $8 \mathrm{mg} / \mathrm{m}^{2}$ so as not to interfere in the formation of the phosphate layer. The mass and porosity of the phosphate layer must be less than $3.5 \mathrm{~g} / \mathrm{m}^{2}$ and $1.5 \%$, respectively, in order to ensure a good atmospheric corrosion resistance of the coating system. The type of cationic resin also influences the corrosion resistance of steels. The best results of corrosion resistance are obtained with modified epoxy resin.
\end{abstract}

Key words: Surface cleanness; Phosphatization; Painting; Atmospheric corrosion resistance.

\section{INTRODUÇÃO}

O sistema de pintura empregado pelas indústrias envolve o substrato metálico, o pré-tratamento de fosfatização e a aplicação de pintura cataforética e de mais três camadas de tinta.

Durante o processo de produção de aços são empregadas emulsões de óleos de laminação, com finalidade de lubrificar e refrigerar o processo de laminação a frio. Quando o óleo de laminação a frio não é totalmente removido durante a produção do aço, principalmente na etapa de limpeza eletrolítica, pode ocorrer formação de carbono grafítico na seção de tratamento térmico da bobina. (1) $O$ craqueamento de óleo de laminação e sua consequente eliminação da superfície da tira dependem do tempo, da temperatura e da composição química da atmosfera do tratamento térmico.

A presença de carbono grafítico sobre a superfície do aço, conhecido como resíduo carbonoso, ocasiona problemas de formação de camadas de fosfatos ou de aderência de revestimentos metálicos em processos de galvanização eletrolítica ou por imersão a quente. O resíduo carbonoso uma vez formado não é eliminado por meio de desengraxamento convencional e, por isso, deve ser evitado durante o processo de produção do aço. É importante esclarecer que os resíduos carbonosos ocorrem somente

\footnotetext{
' Engenheiro Químico, Dr., CQE/ASQ, Pesquisador Especialista Sênior do Centro de Tecnologia Usiminas, Unidade Ipatinga, Av. Pedro Linhares Gomes, 543I, Bairro Usiminas, Cep 36160-900, Ipatinga, MG, Brasil. E-mail: evandro.alvarenga@usiminas.com
} 
em aços sem revestimentos metálicos. Em aços revestidos com zinco e suas ligas aparecem resíduos oleosos sobre a superfície, que são oriundos de produtos orgânicos empregados no processamento final desses materiais nas indústrias de um modo geral. Tecnicamente, as indústrias deveriam empregar produtos orgânicos de fácil remoção; mas, quando não o fazem, a presença de resíduos orgânicos causa o mesmo efeito de resíduos carbonosos em aços sem revestimentos metálicos.

pré-tratamento de fosfatização consiste, inicialmente, no desengraxamento para remoção de óleos de proteção temporária, de óleos de conformação, de graxas e de outros resíduos provenientes do próprio processo, seguido da fosfatização propriamente dita. A remoção de todos os resíduos orgânicos é importante para a formação da camada de fosfato.

A principal finalidade das camadas de fosfato é atuar como superfície de ancoragem para sistema de pintura, promovendo sua aderência, sua flexibilidade e ajudando a proteger o substrato metálico contra corrosão, além disso, também atua como lubrificante sólido durante os processos de conformação mecânica.

A formação de camada de fosfato sobre os aços ocorre por precipitação ou pseudoconversão química, como resultado de cinco etapas fundamentais:(2) i) dissolução de filmes de óxido presentes na superfície do substrato metálico (não se trata de óxidos oriundos de processos de corrosão intensa); ii) ataque eletroquímico da superfície metálica pelo ácido fosfórico (ácido livre) presente na solução fosfatizante, ocasionando deslocamento do equilíbrio químico entre os fosfatos de zinco primário, secundário e terciário; iii) precipitação de cristais de fosfatos extremamente pequenos, formando uma camada, algumas vezes denominada amorfa; iv) cristalização grosseira dos fosfatos formados; v) reorganização cristalina dando origem à estrutura final do recobrimento. A presença de resíduos carbonosos ou oleosos impede o ataque ácido e, consequentemente, a cobertura completa da superfície metálica pela camada de fosfato, criando poros por onde se iniciam os processos corrosivos.

A massa, o tipo de fase cristalina presente e a porosidade são parâmetros importantes para $\circ$ bom desempenho da camada de fosfato.

A pintura, por sua vez, protege o metal contra a corrosão e confere boa aparência ao produto final.

Neste estudo, apresentam-se os efeitos de resíduos carbonosos ou oleosos na formação da camada de fosfato, juntamente com o tipo de resina utilizada na pintura cataforética na resistência à corrosão de aços destinados à indústria automobilística.

\section{MATERIAIS E MÉTODOS}

\section{I Substratos Metálicos}

Foram utilizados aços carbono-manganês e aços galvanizados por imersão a quente sem e com tratamento térmico da camada de zinco (Usigal-Gl e Usigal-GA, com massas de revestimento metálico de $60 / 60 \mathrm{~g} / \mathrm{m}^{2}$ e $40 / 40 \mathrm{~g} / \mathrm{m}^{2}$, respectivamente). Corpos-de-prova desses aços, obtidos a partir de bobinas industriais, foram desengraxados em laboratório e fosfatizados e pintados em empresas do setor automobilístico, aplicando-se dois tipos de resinas catiônicas: epóxi e epóxi modificada. $\mathrm{Na}$ Tabela I têm-se as composições químicas típicas dos substratos metálicos desses aços.

\subsection{Limpeza Superficial dos Aços}

A limpeza superficial dos aços foi avaliada pelos teores de resíduos carbonosos ou oleosos, utilizando-se o equipamento RC-4I 2 da Leco Corporation. Para aços carbono-manganês sem revestimento metálico a temperatura de teste é de $600^{\circ} \mathrm{C}$ e para aços revestidos com zinco e suas ligas de $400^{\circ} \mathrm{C}$.

\subsection{Determinação de Massa, Porosidade e Morfologia de Camada de Fosfato}

A massa de camada de fosfato foi determinada pelo método gravimétrico, imergindo-se cinco corpos-de-prova em solução a $0,5 \% \mathrm{p} / \mathrm{v}$ de $\mathrm{CrO}_{3}$ a $70^{\circ} \mathrm{C}$ durante cinco minutos. Para o cálculo da massa aplica-se a Equação I:

$$
M_{p}=\frac{\left(M_{i}-M_{f}\right)}{A}
$$

sendo:

- $M_{p}=$ massa de camada de fosfato $\left[\mathrm{g} / \mathrm{m}^{2}\right]$,

- $\mathrm{M}_{\mathrm{i}}=$ massa inicial do corpo-de-prova com a camada de fosfato [g],

- $\mathrm{M}_{\mathrm{f}}=$ massa final do corpo-de-prova após a remoção da camada de fosfato [g],

- $\mathrm{A}=$ área do corpo-de-prova $\left[\mathrm{m}^{2}\right]$.

A porosidade da camada de fosfato foi medida em cinco corpos-de-prova fazendo-se uso da Equação 2:(3)

$$
P_{C F}=\frac{I_{m c f}}{I_{m s f}} \times 100
$$

onde:

- $\mathrm{P}_{\mathrm{CF}}=$ porosidade da camada de fosfato [\%],

Tabela I. Composição química típica de substratos metálicos de aços carbono-manganês, Gl e GA

\begin{tabular}{lcccccccc}
\hline \multicolumn{1}{c}{ Tipo de Aço } & \multicolumn{7}{c}{ Composição Química (\% p/p) } \\
\cline { 2 - 9 } & $\mathbf{C}$ & $\mathbf{M n}$ & $\mathbf{S}$ & $\mathbf{P}$ & $\mathbf{S i}$ & $\mathbf{T i}$ & $\mathbf{N b}$ & $\mathbf{A l}$ \\
\hline Carbono-manganês & 0,053 & 0,24 & 0,007 & 0,013 & 0,012 & não tem & não tem & 0,045 \\
Gl e GA & 0,0018 & 0,14 & 0,008 & 0,011 & 0,010 & 0,057 & $<0,005$ & 0,047 \\
\hline
\end{tabular}


- $\mathrm{I}_{\mathrm{mcf}}=$ densidade de corrente média do aço com camada de fosfato $\left[\mathrm{A} / \mathrm{cm}^{2}\right]$,

- $\mathrm{I}_{\mathrm{msf}}=$ densidade de corrente média do aço sem camada de fosfato $\left[\mathrm{A} / \mathrm{cm}^{2}\right]$.

Os valores médios de corrente dos aços com e sem fosfato $\left(I_{m c f}\right.$ e $\left.I_{m s f}\right)$ foram obtidos mediante duas técnicas: i) aço carbono-manganês - técnica eletroquímica de polarização catódica, pela qual se mede a taxa de redução de oxigênio em solução de $\mathrm{NaOH}$ com $\mathrm{pH}$ igual a $12^{(4)}$ e ii) aços revestidos com zinco e suas ligas - técnica eletroquímica de polarização catódica voltamétrica, com eletrólito de solução $0,5 \mathrm{~N}$ de sulfato de sódio $\left(\mathrm{Na}_{2} \mathrm{SO}_{4}\right)$ a $25^{\circ} \mathrm{C}$. (3) Em ambos os casos o equipamento utilizado foi o EG \& G Princeton Applied Research, modelo 273A.

As análises relativas às morfologias da camada de fosfato foram feitas em microscópio eletrônico de varredura modelo EVO 50 da Zeiss, com tensão de aceleração de $20 \mathrm{kV}$, acoplado a espectrômetro por dispersão de energia (EDS), modelo INCA 350 e espectrômetro por dispersão de comprimento de onda (WDS), modelo INCA 500i, ambos da Oxford.

\subsection{Preparação de Corpos-de-prova}

Após desengraxamento, fosfatização e aplicação de pintura antes dos testes de corrosão, as bordas e as regiões de furos dos corpos-de-prova, bem como áreas contendo marcas de identificação, foram protegidas com demão de tinta bicomponente epóxi poliamida. Em seguida, a película de tinta relativa a uma das faces de cada corpo-de-prova foi danificada mecanicamente com ferramenta de usinagem, com ponta de carbeto de tungstênio, até atingir o metal base, formando ângulo interno de $60^{\circ} \pm 15^{\circ}$. O entalhe é feito na diagonal do corpo-de-prova, observando-se uma distância da extremidade do risco até as bordas de, aproximadamente, $20 \mathrm{~mm}$, seguindo a norma NBR 8754. ${ }^{(5)} \mathrm{Na}$ Figura I apresenta-se o aspecto final de corpo-de-prova após esse procedimento.

A espessura de película seca de tinta foi medida utilizando-se equipamento Fischerscope MMS da Fischer Instrument, conforme previsto na norma NBR 10443(6) e a aderência, pelo método de tração. Para se obter a aderência cola-se sobre a película seca de tinta um carretel de alumínio com diâmetro de 19,7 mm. O adesivo empregado foi do tipo estrutural (SGA 394I e SGA 3942 da Threebond, na proporção de I:I). A seguir, os carreteis são destacados mediante teste de tração mecânica, empregando-se máquina de tração do tipo Instron modelo 3365 de 500 kgf, com velocidade de tração de $5 \mathrm{~mm} / \mathrm{min}$ até a ruptura.

Após os testes de corrosão, os corpos-de-prova foram avaliados quanto ao avanço médio e à penetração máxima de corrosão.(2) ${ }^{(2)}$ avanço médio de corrosão representa o quanto a película seca de tinta desprende-se

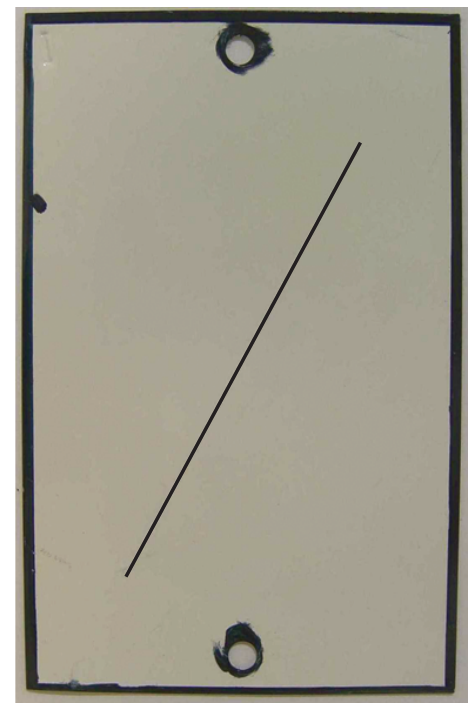

Figura I. Corpo-de-prova com bordas e regiões de furos protegidas com tinta bicomponente epóxi poliamida e com danificação mecânica intencional na película seca de tinta.

da superfície do substrato metálico ao longo da danificação mecânica. A penetração máxima de corrosão também é medida ao longo do risco, mas no sentido da espessura, ou seja, perpendicular à superfície do corpo-de-prova.

\subsection{Testes de Corrosão}

\subsection{Teste acelerado cíclico de corrosão Ciclado I}

Este teste foi desenvolvido na Usiminas e tem duração de 1.680 horas, compreendendo dez ciclos de 168 horas. Cada ciclo consiste das seguintes etapas:

- I० dia - 24 horas de exposição em câmara de névoa salina ${ }^{(7)}$ a $35^{\circ} \mathrm{C} \pm 2{ }^{\circ} \mathrm{C}$, utilizando solução a $5 \% \mathrm{p} / \mathrm{v}$ de $\mathrm{NaCl}$ e $\mathrm{pH}$ de 6,5 a 7,0 ;

- $2^{\circ}$ ao $5^{\circ}$ dia -8 horas de exposição em câmara úmida ${ }^{(8)}$ a $40^{\circ} \mathrm{C} \pm 3^{\circ} \mathrm{C}$ e umidade relativa maior que $95 \%$, seguida de 16 horas nessa câmara, porém desligada, aberta e à temperatura ambiente;

- $6^{\circ}$ e $7^{\circ}$ dia - exposição em ambiente de laboratório.

A câmara utilizada na execução do teste Ciclado I foi a Q-Fog da Q-Panel Company com volume de I. $100 \mathrm{~L}$.

\subsubsection{Teste acelerado cíclico de corrosão GM 9540P}

O teste GM 9540P(9) foi desenvolvido na General Motors e sua duração é de 1.920 horas, correspondendo a 80 ciclos de 24 horas. Cada ciclo compõe-se das etapas seguintes: 
- aplicação de névoa salina mista ${ }^{(7)}(0,9 \% \mathrm{p} / \mathrm{v}$ de $\mathrm{NaCl}, 0,1 \% \mathrm{p} / \mathrm{v}$ de $\mathrm{CaCl}_{2}$ e $0,25 \% \mathrm{p} / \mathrm{v}$ de $\mathrm{NaHCO}_{3}$ ) durante 15 minutos, seguida de intervalos de 75 minutos em câmara úmida ${ }^{(8)}$ a $25^{\circ} \mathrm{C} \pm 2{ }^{\circ} \mathrm{C}$ e umidade relativa entre $40 \%$ a $50 \%$. Essa etapa deve ser repetida quatro vezes antes de passar para a seguinte;

- 2 horas em câmara úmida ${ }^{(8)}$ a $25^{\circ} \mathrm{C} \pm 22^{\circ} \mathrm{C}$ e umidade relativa entre $40 \%$ e $50 \%$;

- 8 horas em câmara úmida ${ }^{(8)}$ a $49^{\circ} \mathrm{C} \pm 2^{\circ} \mathrm{C}$ e umidade relativa entre $95 \%$ e $100 \%$;

- 8 horas de câmara seca ${ }^{(8)} \mathrm{a} 60^{\circ} \mathrm{C} \pm 22^{\circ} \mathrm{C}$ e umidade relativa menor que $30 \%$.

A câmara utilizada na execução do teste GM 9540P foi a Q-Fog da Q-Panel Company com volume de I. $100 \mathrm{~L}$.

\subsubsection{Teste não-acelerado de corrosão em atmosfera marinha}

Este teste foi realizado segundo prescreve a norma NBR 70 I I $^{(10)}$ utilizando-se a Estação de Corrosão Marinha da Usiminas, localizada na latitude $23^{\circ} 00^{\prime} 49^{\prime \prime} S$ e na longitude 42॰00'56"O, em Arraial do Cabo-RJ.(II)

\section{RESULTADOS E DISCUSSÃO}

\section{I Influência da Limpeza Superficial dos Aços na Porosidade de Camada de Fosfato}

A limpeza superficial dos aços foi medida em termos de resíduos carbonosos/oleosos. O mapeamento de carbono por microanálise por espectrometria de raios-X por dispersão de energia realizada em camadas de fosfato indica falhas de formação dessa camada em regiões de altos teores de resíduos carbonosos, em contraste àquelas superfícies com baixa contaminação de carbono, conforme mostrado nas Figuras 2 e 3.

A influência de resíduos carbonosos na formação de camadas de fosfato pode ser explicada em virtude do processo de fosfatização envolver dissolução anódica do substrato metálico (ferro ou zinco). A presença de carbono como contaminante superficial obstrui tanto a criação de sítios ativos como a reação anódica de fosfatização; consequentemente, impede as reações catódicas responsáveis pela precipitação de cristais de fosfato. $O$ resultado do aumento dos teores de resíduos carbonosos é o incremento da porosidade de camada de fosfato, principalmente para valores acima de $8,0 \mathrm{mg} / \mathrm{m}^{2}$, conforme apresentado no gráfico da Figura 4.

A razão pela qual a porosidade de camadas de fosfato cresce repentinamente, quando os teores dos resíduos carbonosos são maiores do que $8,0 \mathrm{mg} / \mathrm{m}^{2}$, está no tamanho desses resíduos. Observado por microscopia eletrônica, os resíduos carbonosos são um aglomerado de pós de carbono cujo estado físico é próximo ao da grafite. $O$ diâmetro desse aglomerado em amostras com alta contaminação de carbono varia de $10 \mu \mathrm{m}$ a $100 \mu \mathrm{m}$, coerentemente com o tamanho de poros de camadas de fosfato. Por exemplo, o diâmetro de poros da amostra da Figura 3b é cerca de $80 \mu \mathrm{m}$. Comparativamente, o diâmetro médio de cristais de fosfato da amostra da Figura $3 \mathrm{a}$ é de $3 \mu \mathrm{m}$, portanto, menor que o diâmetro de resíduos carbonosos e de poros em camada de fosfato. Desta forma, se a quantidade de resíduos carbonosos é menor que $8,0 \mathrm{mg} / \mathrm{m}^{2}$, o diâmetro de seus aglomerados é suficientemente pequeno para não interferir na criação de sítios ativos sobre a superfície metálica (de acordo com Cheever, ${ }^{(12)}$ o número desses sítios é de $10^{5}$ sítios $/ \mathrm{cm}^{2}$ a

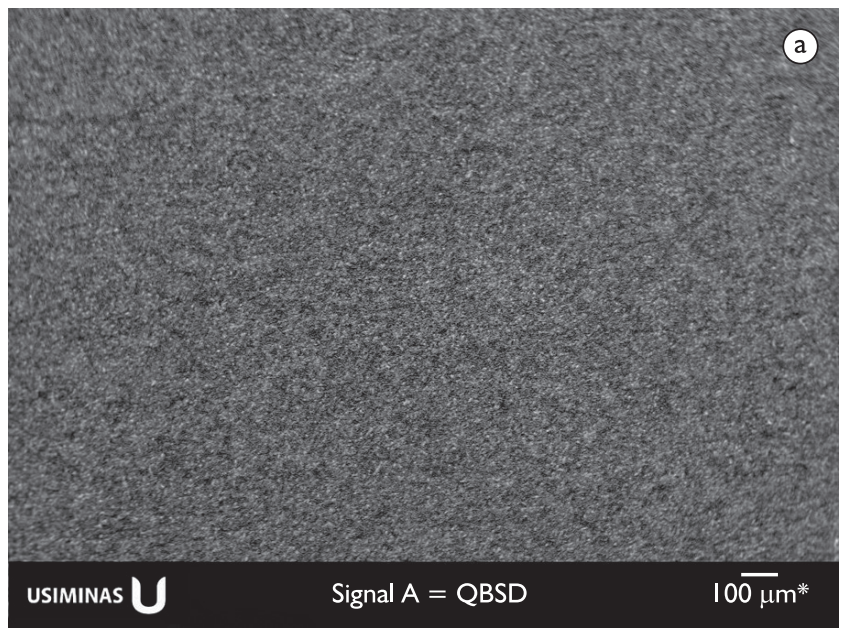

Teor de resíduo carbonoso médio de $4 \mathrm{mg} / \mathrm{m}^{2}$

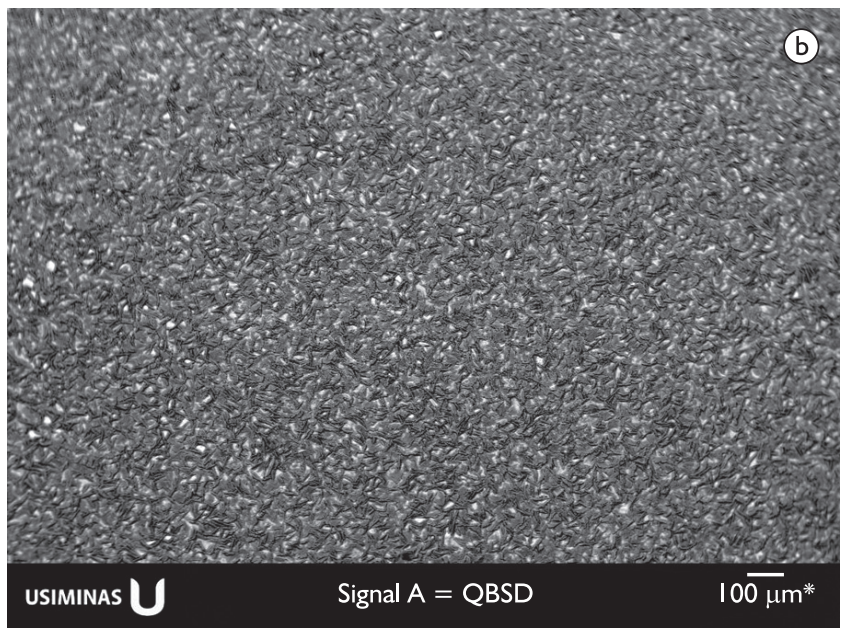

Teor de resíduo carbonoso médio de $15 \mathrm{mg} / \mathrm{m}^{2}$

Figura 2. Mapeamento de carbono por espectrometria de raios-X (pontos brancos) em amostra fosfatizada. Os poros na camada de fosfato coincidem com presença de carbono (resíduo carbonoso). 


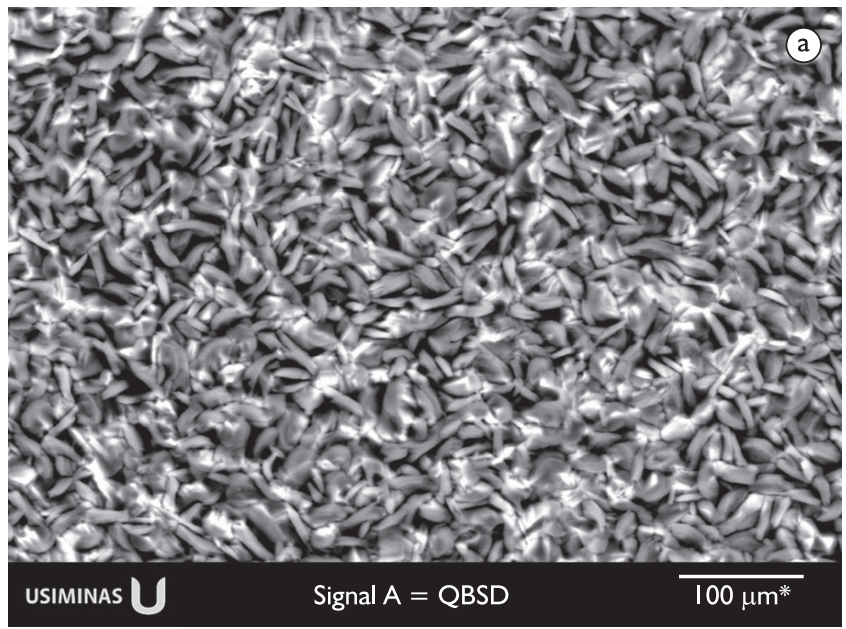

Amostra com teor de resíduo carbonoso menor que $8 \mathrm{mg} / \mathrm{m}^{2}$

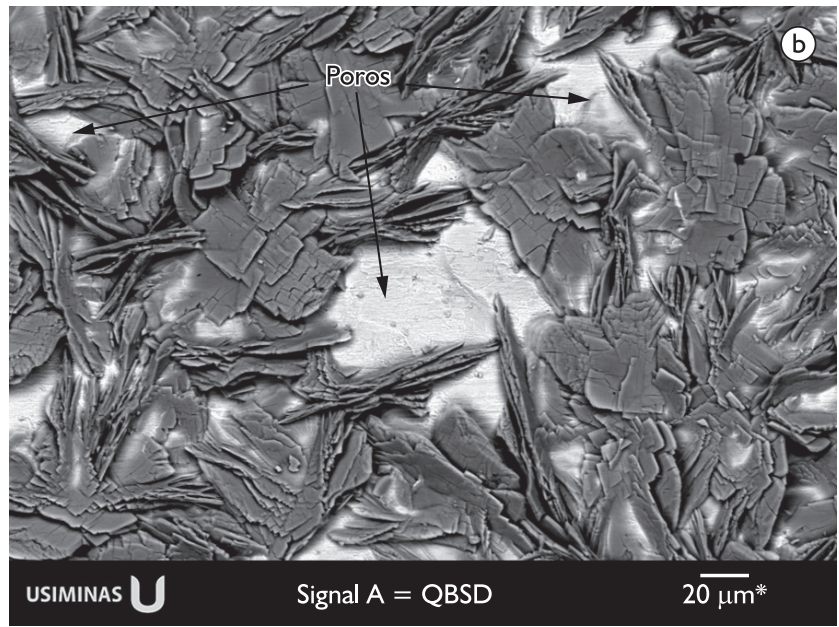

Amostra com teor de resíduo carbonoso maior que $14 \mathrm{mg} / \mathrm{m}^{2}$

Figura 3. Influência de resíduo carbonoso na formação de poros na camada de fosfato.

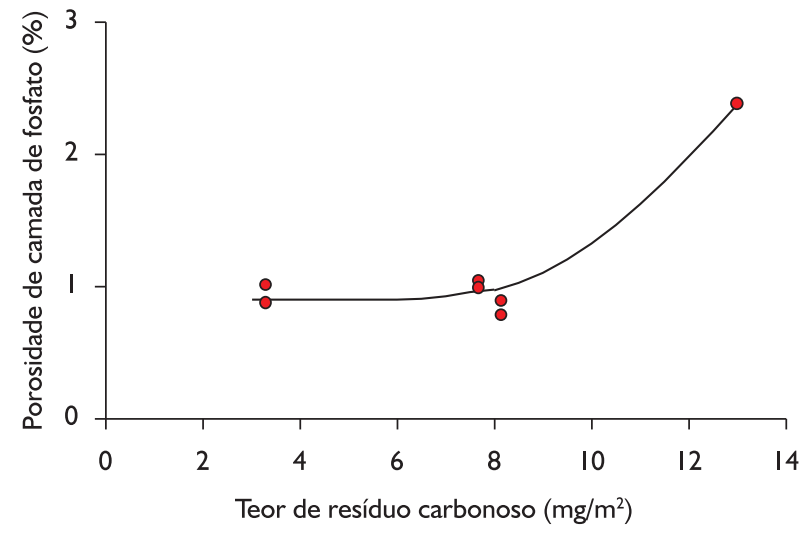

Figura 4. Influência de resíduo carbonoso na porosidade de camadas de fosfato de aços carbono-manganês.
$10^{6}$ sítios $\left./ \mathrm{cm}^{2}\right)$. Quanto maior a taxa de formação de sítios ativos menores serão os cristais de fosfato, a cristalinidade tende a ser bem mais acentuada (agulhas, plaquetas, pétalas), melhor é a cobertura do substrato metálico pela camada de fosfato e menor a porosidade dessa camada, conforme ilustrado na Figura 5a. Por outro lado, aglomerados de pós de carbono maiores, correspondendo a resíduos carbonosos acima de $8,0 \mathrm{mg} / \mathrm{m}^{2}$, impedem a formação de sítios ativos prejudicando a nucleação de cristais de fosfato. Com isso, os cristais tendem a ficar maiores e mais frágeis, perdem a cristalinidade (aspecto mais amorfo), crescem lateralmente e não conseguem recobrir toda a área a ser fosfatizada (Figura 5b).
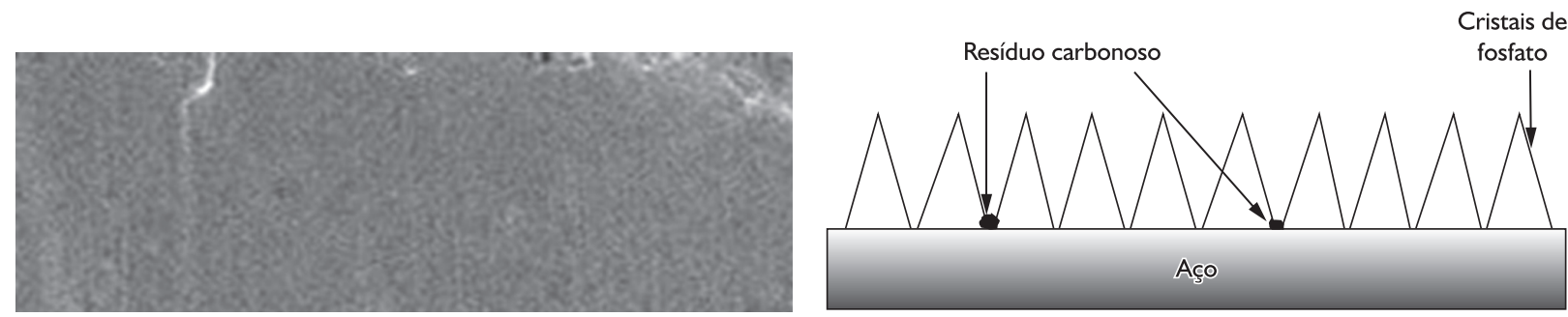

Superfície com baixa contaminação de carbono

(b)

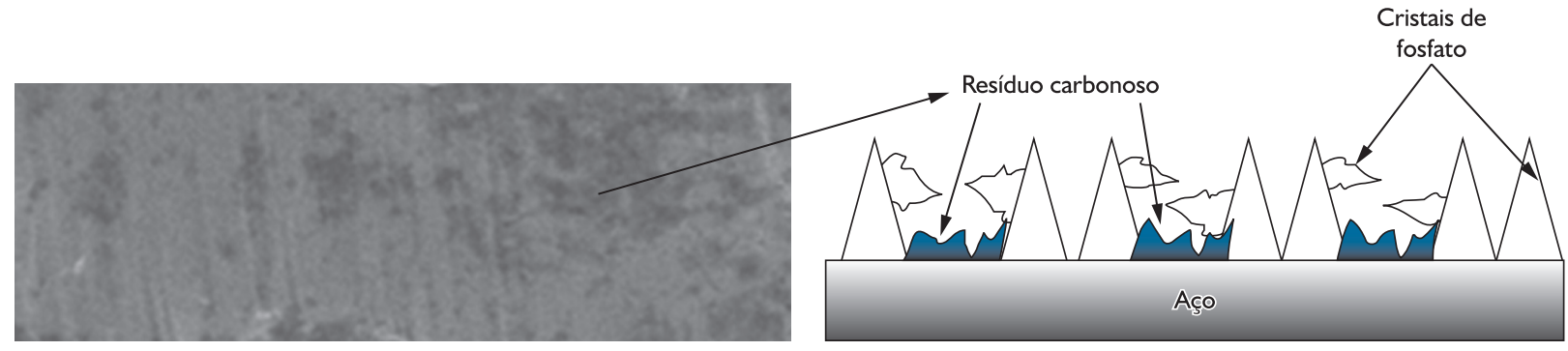

Superfície com alta contaminação de carbono

Figura 5. Ilustração de influência de contaminações orgânicas na superfície de substratos metálicos na formação de camadas de fosfato. 


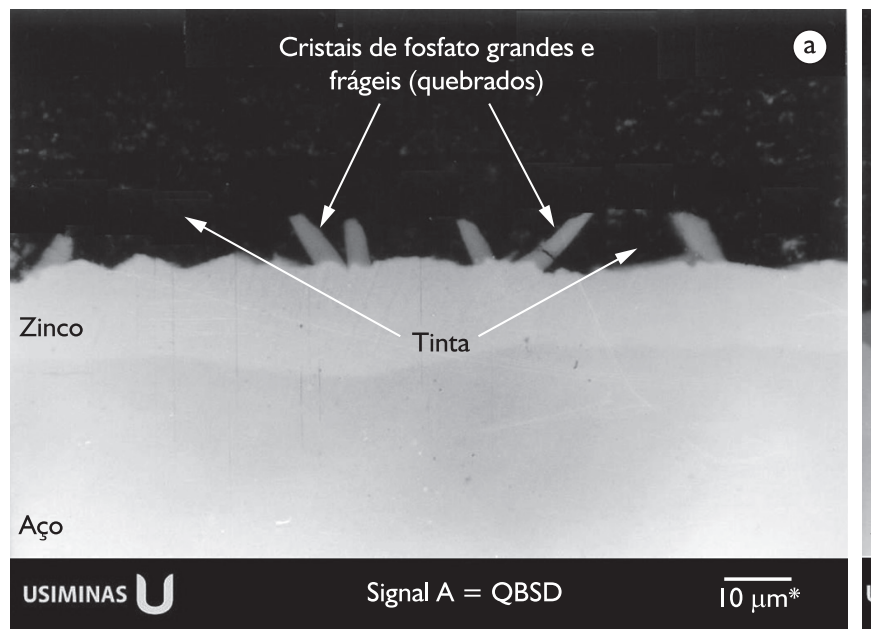

Cristal de fosfato frágil

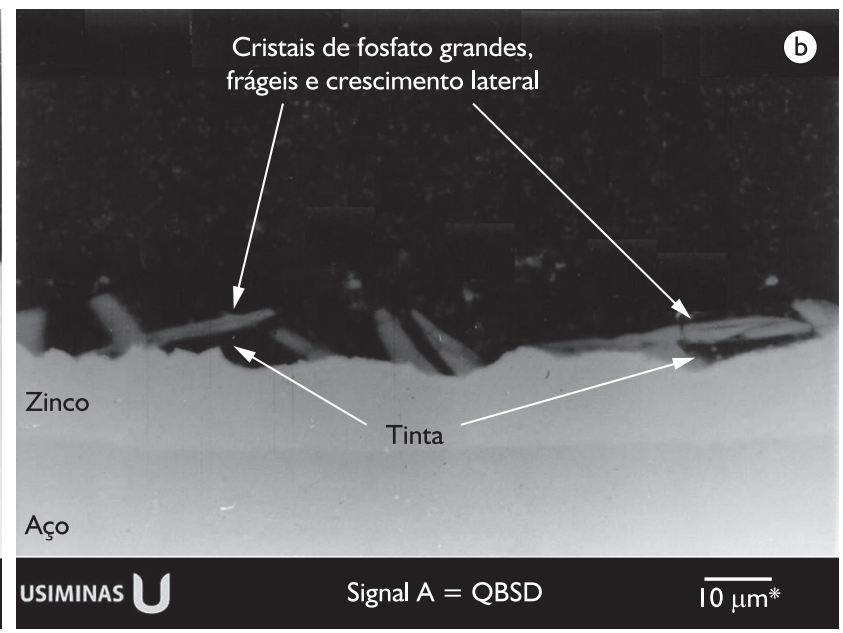

Crescimento inadequado (lateral) de cristais de fosfato

Figura 6. Aspectos de fragilidade e de crescimento inadequado de cristais de fosfato devido à presença de resíduos carbonosos maiores que $10 \mathrm{mg} / \mathrm{m}^{2}$ na superfície do metal.

A fragilidade de cristais de fosfato devido ao seu tamanho e seu crescimento lateral pode ser observada na Figura 6.

\subsection{Efeito do Tamanho de Cristais de Fosfato na Porosidade de Camada de Fosfato}

A preparação da superfície metálica para receber camadas de fosfato, normalmente criando-se sítios ativos mediante aplicação de solução de titânio coloidal, tem a finalidade de refinar ou controlar o tamanho de cristais de fosfato. Esse parâmetro é importante, pois quanto menor for o tamanho de cristais mais fácil é sua acomodação um ao lado do outro e melhor será a cobertura da superfície metálica. Na Figura 7 mostra-se a relação entre o tamanho de cristais de fosfato e a porosidade de sua camada. Segundo esta figura, a porosidade da camada de fosfato aumenta rapidamente para cristais de dimensões maiores do que $3,4 \mu \mathrm{m}$.

\subsection{Efeito de Camada de Fosfato na Aderência de Sistema de Pintura dos Aços}

Como já mencionado, a fixação de película de tinta sobre substratos metálicos é feita por meio de camada de fosfato, que atua como superfície de ancoragem. A permeação da tinta entre a rede de cristais da camada de fosfato pode ser vista na Figura 8, o que evidencia que sua fixação é mecânica.

Devido à fixação da película seca de tinta ser mecânica, tornam-se importantes a completa cobertura da superfície metálica e a integridade de cristais de fosfato. $\mathrm{Na}$ Figura 9 apresentam-se as relações entre o tamanho de cristal e a massa de camada de fosfato na aderência de películas secas de tinta, parâmetros que devem ser levados em conta em sistemas de pintura.

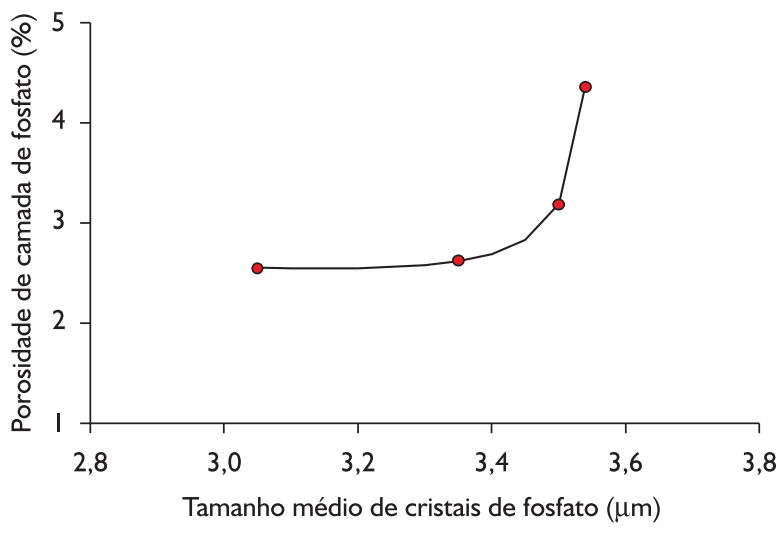

Figura 7. Relação entre o tamanho de cristais de fosfato e a porosidade da camada de fosfato.

Conforme evidenciado na Figura 9, a tensão necessária para remover a película seca de tinta (aderência) de corpos-de-prova fosfatizados e pintados decresce com - tamanho de cristais de fosfato e, de forma acentuada, para massas de camadas de fosfato acima de $3,5 \mathrm{~g} / \mathrm{m}^{2}$. Isso ocorre porque, uma vez nucleados todos os cristais de fosfato, a massa de camada aumenta mediante crescimento dos cristais, o que os tornam mais frágeis e quebradiços, comprometendo a aderência do filme de tinta.

\subsection{Influência da Porosidade de Camada de Fosfato na Resistência à Corrosão dos Aços}

Estudos $^{(3,13)}$ sobre porosidade de camadas de fosfatos descrevem efeitos marcantes desse parâmetro na resistência à corrosão de aços fosfatizados e pintados, conforme mostrado nas Figuras 10 e II. 


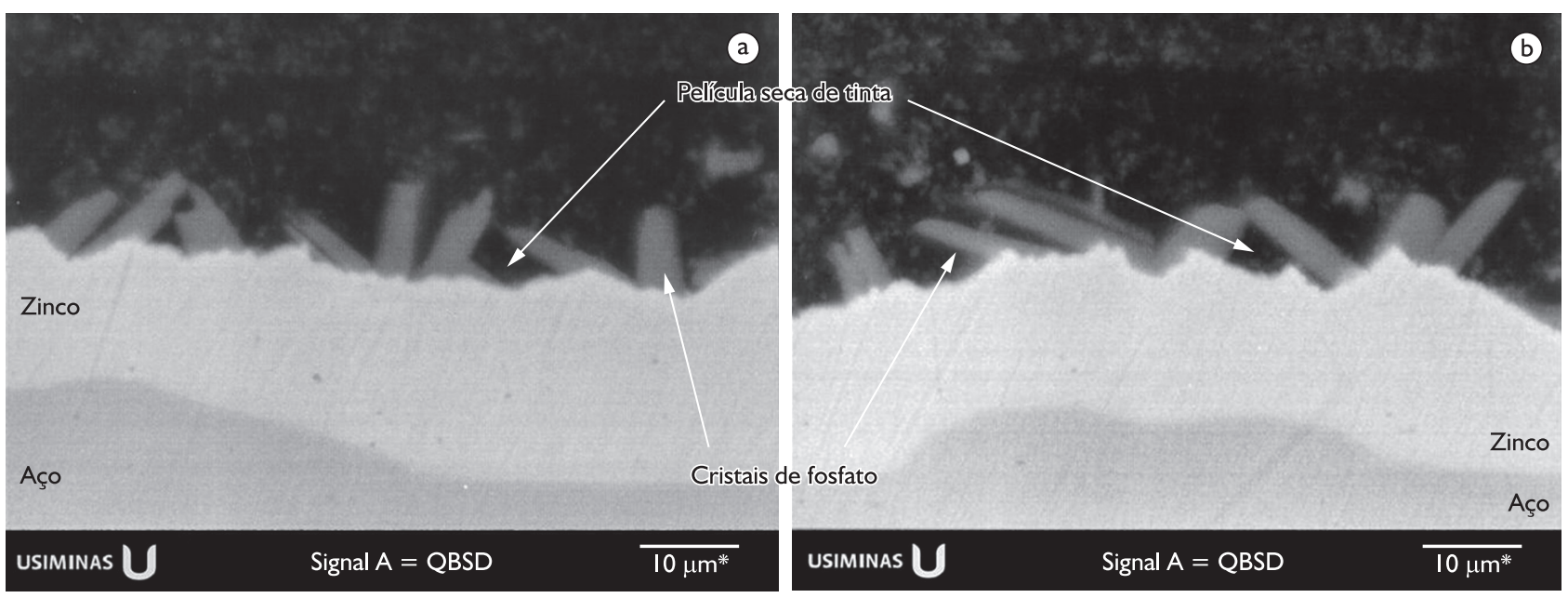

Figura 8. Exemplo de permeação de película de tinta entre a rede cristalina da camada de fosfato.
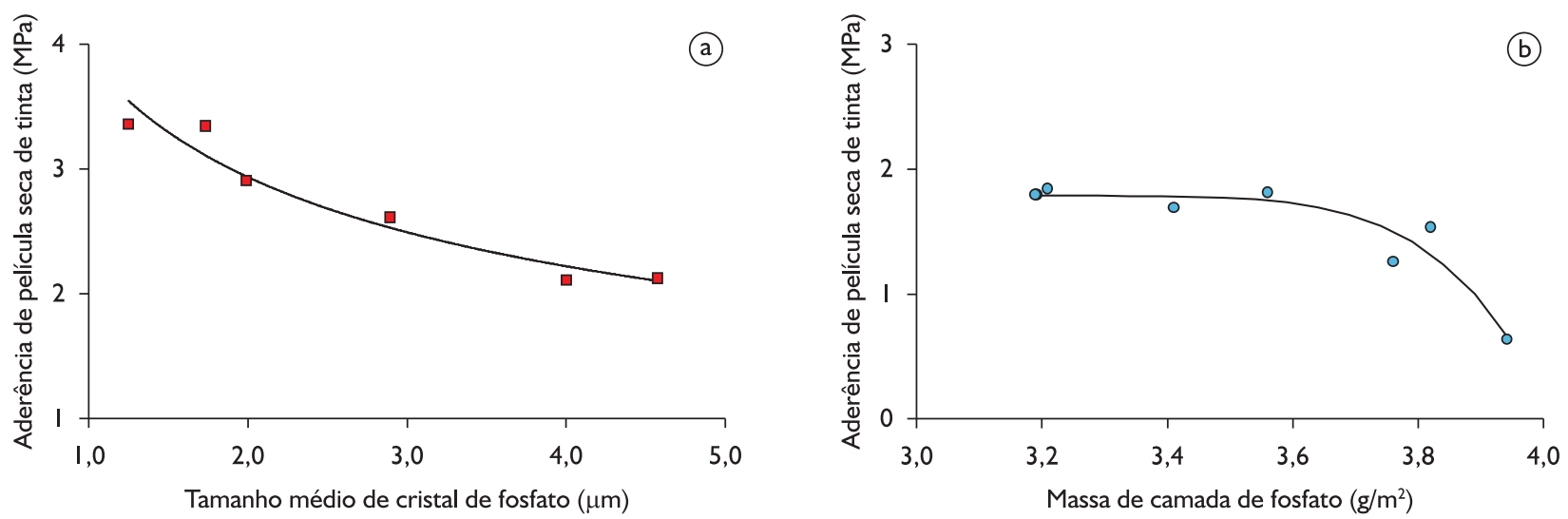

Figura 9. Resultados de aderência de película seca de tinta medida pelo método de tração em função de tamanho de cristal de fosfato e de massa de camada de fosfato.

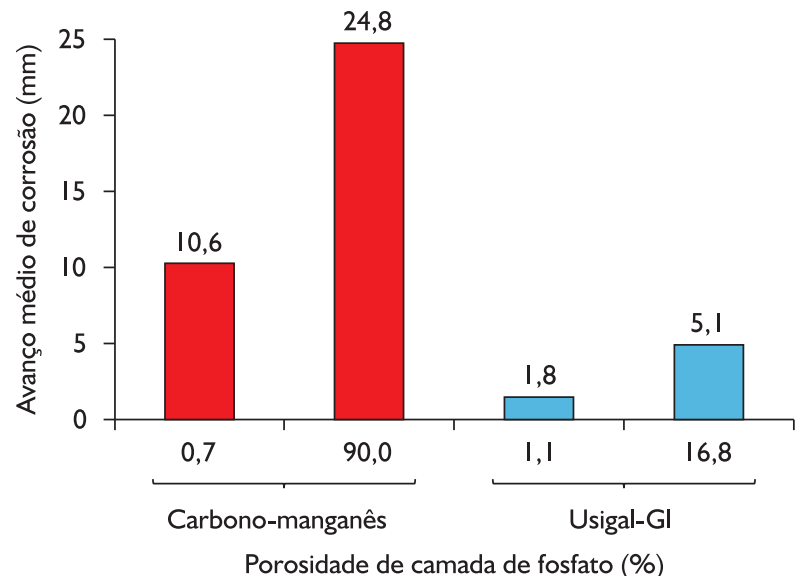

Figura 10. Influência da porosidade de camada de fosfato na resistência à corrosão de aços fosfatizados e pintados. Teste acelerado cíclico de corrosão Ciclado I.

Observa-se, na Figura 10, que os aços carbono-manganês são mais sensíveis ao efeito da porosidade de camada de fosfato do que os aços galvanizados por imersão a quente sem tratamento da camada de zinco.

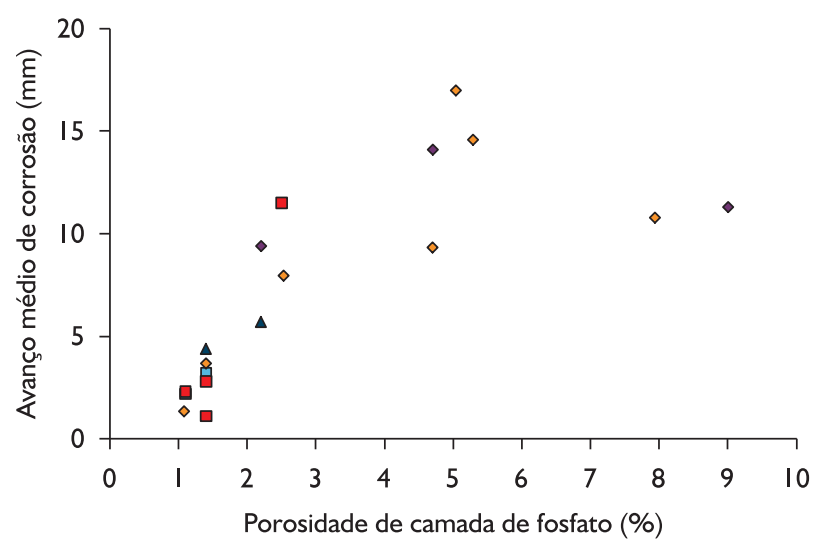

Figura II. Relação entre porosidade de camada de fosfato e avanço médio de corrosão. Testes acelerados cíclicos de corrosão Ciclado I e GM 9540P e não-acelerado de corrosão em atmosfera marinha.

Na Figura II apresenta-se a influência da porosidade da camada de fosfato na resistência à corrosão de aços fosfatizados e pintados, plotando-se na mesma figura resultados de testes acelerados e não-acelerado de 
corrosão. Observa-se que, para atingir avanços médios de corrosão menores que $5 \mathrm{~mm}$, a porosidade da camada de fosfato deve ser inferior a 1,5\%.

\subsection{Efeito de Pintura Eletroforética na Resistência à Corrosão de Aços}

De acordo com os resultados apresentados na Figura 12, o sistema de pintura eletroforética com resina epóxi modificada apresenta melhor resistência à corrosão, comparativamente ao com resina epóxi convencional.

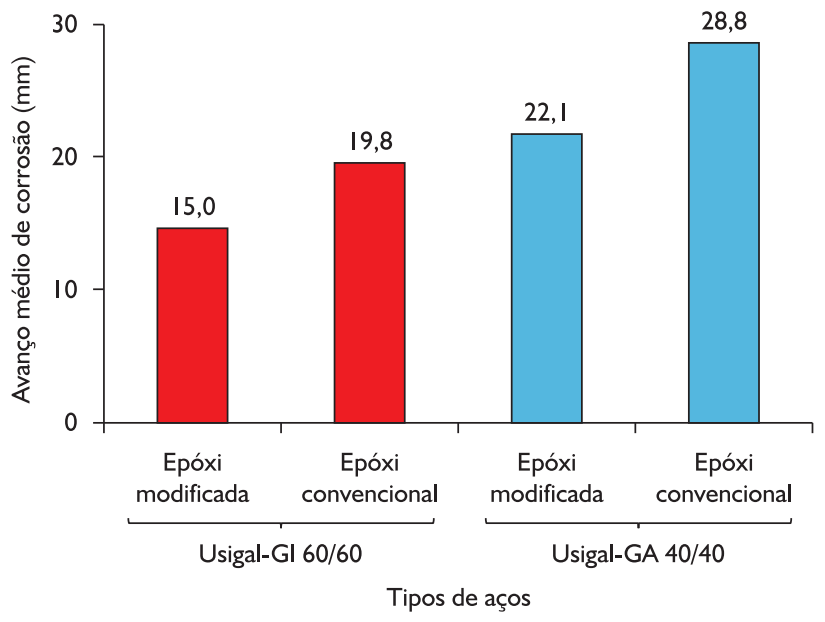

Figura 12. Efeito do tipo de resina empregada na pintura eletroforética na resistência à corrosão de aços. Teste acelerado cíclico de corrosão GM 9540P com 5.760 horas de duração.

Apesar das resinas epóxi serem, de modo geral, boas para a proteção contra corrosão de metais, a mistura de diferentes tipos de resinas pode resultar em produtos com melhor desempenho.
Nos resultados apresentados na Figura 12, o melhor desempenho do aço Usigal-Gl $60 / 60 \mathrm{~g} / \mathrm{m}^{2}$ deve-se a sua maior massa de camada de zinco, comparativamente ao aço Usigal-GA $40 / 40 \mathrm{~g} / \mathrm{m}^{2}$.

\section{CONCLUSÃO}

Verifica-se, neste trabalho, que parâmetros de processo de pintura, tais como limpeza superficial, tamanho de cristal, massa e porosidade de camada de fosfato e tipo de resina cationica interferem na resistência à corrosão de aços fosfatizados e pintados. Dentre esses parâmetros destaca-se a limpeza superficial, cuja medida em termos de resíduos carbonosos/oleosos deve ser menor que $8 \mathrm{mg} / \mathrm{m}^{2}$, pois é a partir de superfícies metálicas isentas de resíduos orgânicos que a camada de fosfato irá ser depositada e, posteriormente, o filme de tinta irá se assentar. $\mathrm{O}$ tamanho de cristais de fosfato, a porosidade de camada de fosfato e a aderência de película seca de tinta são fortemente influenciados pelo teor de carbono na superfície do aço.

A massa de camada de fosfato não deve ultrapassar valores de $3,5 \mathrm{~g} / \mathrm{m}^{2}$, de modo a assegurar a formação de cristais de fosfato menores do que $5 \mu \mathrm{m}$ e porosidade de camada inferior a I,5\%. A utilização de resinas epóxi modificada traz melhores benefícios do que resinas epóxi convencionais.

Somente mediante a combinação de processo de pré-tratamento bem realizado com utilização de resinas para pintura eletroforética com boa resistência à corrosão, que o sistema de pintura atingirá seu melhor desempenho.

\section{REFERÊNCIAS}

I INOKUTI, Y. Formation of graphite on the surface of cold rolled low carbon steel sheet during annealing. Transactions-ISIJ, v. I5, n. 6, p. 3I4-23, June 1975.

2 ALVARENGA, E. A. Influência do substrato metálico e da camada de zinco na resistência à corrosão de aços eletrogalvanizados fosfatizados e pintados. 2007. 233 p. Tese (Doutorado em Engenharia Metalúrgica e de Minas) - Faculdade de Engenharia Metalúrgica e de Minas da Universidade Federal de Minas Gerais, Belo Horizonte, 2007.

3 TEIXEIRA, C. H. S. B.; ALVARENGA, E. A. Resistência à corrosão de aços galvanizados fosfatizados e pintados. In: $10^{a}$ COTEQ - CONFERÊNCIA SOBRE TECNOLOGIA DE EQUIPAMENTOS, 10.; CONBRASCORR - CONGRESSO BRASILEIRO DE CORROSÃO, 28., 2009, Salvador. Anais... Rio de Janeiro, Abraco, 2009. p. I-8.

4 ZURILLA, R. W.; HOSPADARUK, V. Quantitative test for zinc phosphate coating quality. In: CONGRESS AND EXPOSITION COBO HALL, 1978, Detroit. Proceedings... Warrendale: Society of Automotive Engineers, 1978. SAE n. 780187.

5 ASSOCIAÇÃO BRASILEIRA DE NORMAS TÉCNICAS - ABNT. Norma NBR 8754 -Corpos-de-prova revestidos e expostos a ambientes corrosivos: método de avaliação. Rio de Janeiro, 1985.

6 ASSOCIAÇÃO BRASILEIRA DE NORMAS TÉCNICAS - ABNT. Norma NBR 10.443 - Tintas e vernizes: determinação da espessura da película seca sobre superfícies rugosas: método de ensaio. Rio de Janeiro, 2008.

7 ASSOCIAÇÃO BRASILEIRA DE NORMAS TÉCNICAS - ABNT. Norma NBR 8094 - Material metálico revestido e não-revestido: corrosão por exposição à névoa Salina. Rio de Janeiro, 1983. 
8 ASSOCIAÇÃO BRASILEIRA DE NORMAS TÉCNICAS - ABNT. Norma NBR 8095 - Material metálico revestido e não-revestido - corrosão por exposição à atmosfera úmida saturada. Rio de Janeiro, 1983.

9 GENERAL MOTORS ENGINEERING STANDARDS. STANDARD GM 9540P - Accelerated corrosion test. Detroit, 1997.

10 ASSOCIAÇÃO BRASILEIRA DE NORMAS TÉCNICAS - ABNT. Norma NBR 701 I - Materiais metálicos revestidos por pintura: ensaio não-acelerado de corrosão atmosférica: método de ensaio. Rio de Janeiro, 198I.

I I ALVARENGA, E. A. Pesquisa e desenvolvimento em corrosão e em engenharia de superfície na Usiminas: infraestrutura e resultados. In: CONGRESSO ANUAL DA ABM, 64., 2009, Belo Horizonte, MG. Anais... São Paulo, 2009. I CD.

12 CHEEVER, G. D. Formation and growth of zinc phosphate coatings. Journal of Paint Technology, v. 39, n. 504, p. I-I3, Jan. 1967.

13 TEIXEIRA, C. H. S. B.; ALVARENGA, E. A., VASCONCELOS, W. L. Influência da porosidade da camada de fosfato na resistência à corrosão de aços pintados. In: INTERCORR 2008 - CONGRESSO BRASILEIRO DE CORROSÃO, 28.; INTERNATIONAL CORROSION MEETING, 2., 2008, Recife, PE. Anais... Rio de Janeiro: Abraco, 2008. p. I-8.

Recebido em: |4/02/201 I

Aceito em: 10/05/20I I 